\title{
Review Article \\ Comparing Intravenous Insertion Instructional Methods with Haptic Simulators
}

\author{
Lenora A. McWilliams ${ }^{1}$ and Ann Malecha ${ }^{2}$ \\ ${ }^{1}$ University of Houston, 14000 University Blvd., Sugar Land, TX 77479, USA \\ ${ }^{2}$ Texas Woman's University, 6700 Fannin Street, Houston, TX 77030-2343, USA \\ Correspondence should be addressed to Lenora A. McWilliams; lamcwilliams@uh.edu
}

Received 30 June 2016; Accepted 4 January 2017; Published 29 January 2017

Academic Editor: Maria H. F. Grypdonck

Copyright (C) 2017 Lenora A. McWilliams and Ann Malecha. This is an open access article distributed under the Creative Commons Attribution License, which permits unrestricted use, distribution, and reproduction in any medium, provided the original work is properly cited.

Objective. The objective of this review was to compare traditional intravenous (IV) insertion instructional methods with the use of haptic IV simulators. Design. An integrative research design was used to analyze the current literature. Data Sources. A search was conducted using key words intravenous (IV) insertion or cannulation or venipuncture and simulation from 2000 to 2015 in the English language. The databases included Academic Search Complete, CINAHL Complete, Education Resource Information Center, and Medline. Review Methods. Whittemore and Knafl's (2005) strategies were used to critique the articles for themes and similarities. Results. Comparisons of outcomes between traditional IV instructional methods and the use of haptic IV simulators continue to show various results. Positive results indicate that the use of the haptic IV simulator decreases both band constriction and total procedure time. While students are satisfied with practicing on the haptic simulators, they still desire faculty involvement. Conclusion. Combining the haptic IV simulator with practical experience on the IV arm may be the best practice for learning IV insertion. Research employing active learning strategies while using a haptic IV simulator during the learning process may reduce cost and faculty time.

\section{Introduction}

One of the most commonly performed basic nursing skills is intravenous (IV) catheter insertion. IV catheterization, cannulation, or insertion is a complex [1] and invasive procedure [2]. While it is the most common and important skill performed in the clinical setting, it is also a technically difficult procedure [3]. Reinhardt et al. [4] note that learning how to insert an IV catheter is the most challenging skill taught in nursing school. Traditional methods of instruction for IV insertion vary between nursing and medical students. The nursing student IV education typically consists of faculty didactic presentation followed by faculty demonstrating the procedure on an IV arm task trainer. For this teaching method, students practice under faculty supervision followed by a skills competency check off assessment. The traditional teaching method for medical students varies and may consist of didactic instruction followed by either practicing on a simulated arm, practicing the actual procedure on students or patients [5], learning by doing [6], or see-one do-one format [7].

Traditional methods of teaching IV insertion can be time consuming and costly [8]. Sotto et al. [7] state that not only the current methods of teaching IV insertion are cost ineffective but also opportunities for practicing the procedure are inconsistent, with limited variability, and generally delegated to ancillary personnel such as lab assistants. Engum et al. [6] discuss the importance of practitioners developing clinical skills for invasive procedures prior to working with patients. Students need to master high risk skills, such as IV catheter insertion, prior to performance in the clinical setting. Proficiency of IV insertion may prevent serious patient complications including infiltration, phlebitis, or pain [9]. 
The use of patient simulators in education allows students to learn and experience real world situations, while ensuring that patients receive safe, competent treatment as well as reducing cost of instruction and practice [8]. The use of simulators provides opportunities for students to practice and perfect skills in a safe nonthreatening environment [10] while making errors without harm or discomfort to a patient [6]. During simulation, students become active learners [10]. They construct new knowledge by attaching meaning to current or past experiences, which is then assimilated for future encounters [11]. More and more, the skill of IV insertion is being taught with a haptic IV simulator. This device includes a catheter/hub assembly and an interface that allows students to palpate a vein, stretch the skin, and feel resistance during venipuncture. Additionally, during the simulated vein cannulation, a computer screen provides immediate feedback related to bleeding, bruises, and swelling.

Nurse educators must prepare nursing students to be competent as they transition from student to clinical practitioner [12]. Nursing students need opportunities to practice and learn how to perform safe and competent IV insertion or cannulation as inappropriate cannulation may have harmful effects, including infiltrations, phlebitis, and pain [13]. With the increasing use of simulation in nursing education, it is unclear if traditional methods of teaching IV insertion or the use of an IV simulator result in better skill performance competency.

\section{Aim}

An integrated literature review was performed to examine and/or compare traditional IV insertion instructional methods with haptic IV simulators and compare the outcomes of the instructional methods.

\section{Search Methods and Strategy}

A search of the databases Academic Search Complete, CINAHL Complete, Education Resource Information Center and Medline was conducted in order to locate published articles on methods and simulators used to teach IV insertion or cannulation. The search was limited to English language articles published between the years 2000 to 2015. Search terms employed were a combination of intravenous (IV) insertion, cannulation, or venipuncture and simulation. Of the 51 articles retrieved, 11 met the inclusion criteria for research studies utilizing haptic IV simulators for the purpose of teaching IV insertion or cannulation. Whittemore and Knafl's [14] data analysis strategies were used to provide structure and rigor while employing a constant comparison approach to the literature review process. For this integrative review, these strategies included reducing data into subcategories, organizing data using a matrix format, followed by comparison, analysis, and verification of overarching themes and conclusions of the subcategories. Synthesis of these subcategories was then integrated to provide a comprehensive summation of the topic of IV instructional methods using a simulator.

\section{Results}

\subsection{Comparison of Instructional Methods and Performance}

4.1.1. Setting and Sample. Table 1 summarizes the IV simulators and instructional methods for this review. Of the 11 articles reviewed, 6 studies were conducted in the United States while the other 5 studies were conducted in Greece, Hong Kong, Korea, Philippines, and Sweden. The participants varied from nursing students ( $n=5$ studies), to medical students ( $n=2$ studies), to registered nurses ( $n=2$ studies). One study utilized both nursing and medical students while another one used a combination of medical students, graduate medical doctors, and nurses who were experts in IV cannulation.

4.1.2. Teaching and Practice. Almost every study $(n=10)$ compared the use of a haptic IV simulator to more traditional teaching methods. The haptic IV simulators used in these studies included the CathSim Intravenous Training System (CS) from Immersion Medical, Inc., Laerdal's Virtual IV (VIV) training system, and the virtual reality/haptic IV training simulator from the Republic of Korea [3]. The majority of the instructional methods followed a pattern of (a) pretest-lecture-practice-performance testing or (b) lecturepretest-practice-performance testing. Traditional instruction included students practicing on a plastic IV arm $(n=8$ studies), on each other $(n=1)$, on a healthy volunteer $(n=$ $1)$, or on a manikin $(n=1)$.

4.1.3. Skill Performance. In eight of the eleven studies, the students' skill performance was evaluated via actual IV insertion attempt on a patient $[3,4,7,10,13]$ or a human volunteer $[6,8,15]$. For three studies, skill performance was evaluated with the use of an IV arm [5], on a haptic IV simulator [16], or a combination of an IV arm and a haptic simulator [9].

In six studies, the use of a haptic IV simulator or a combination of an IV arm and a haptic IV simulator showed improvement in performance skills. Bowyer et al. [5] indicated that while all groups improved on performance as evaluated by the faculty, the group using the VIV simulator showed greater improvement over the IV arm group. They concluded that both haptic IV simulators (VIV and CS) were at least equal to the traditional method of teaching IV insertion, which is costlier and faculty intensive. Jamison et al. [9] noted that skill performance was moderately related to improved cognitive posttest scores for the CS group.

In three of the eleven studies, students' IV cannulation success rates were compared and no differences were noted between the traditional training method and training on the haptic IV simulator $[4,6,15]$. Chang et al. [13] were unable to determine if one training method was superior to another due to confounding factors and unequal group composition, even though both groups had successful cannulation rates.

However, Sotto et al. [7] found that the group using the VIV simulator had a greater success rate in starting an IV on a patient and lower band constriction and total procedure time than the traditional method of teaching IV 


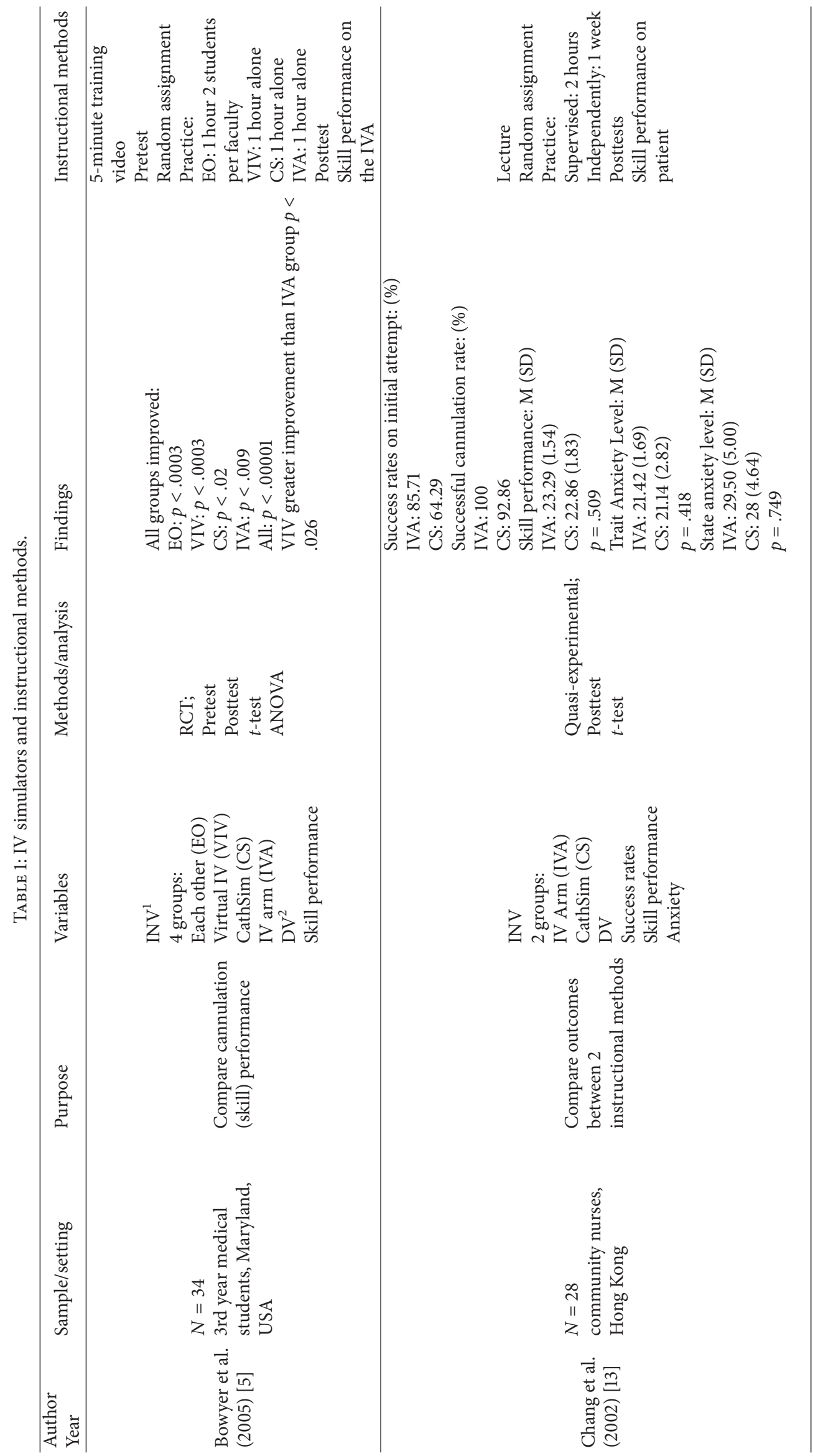




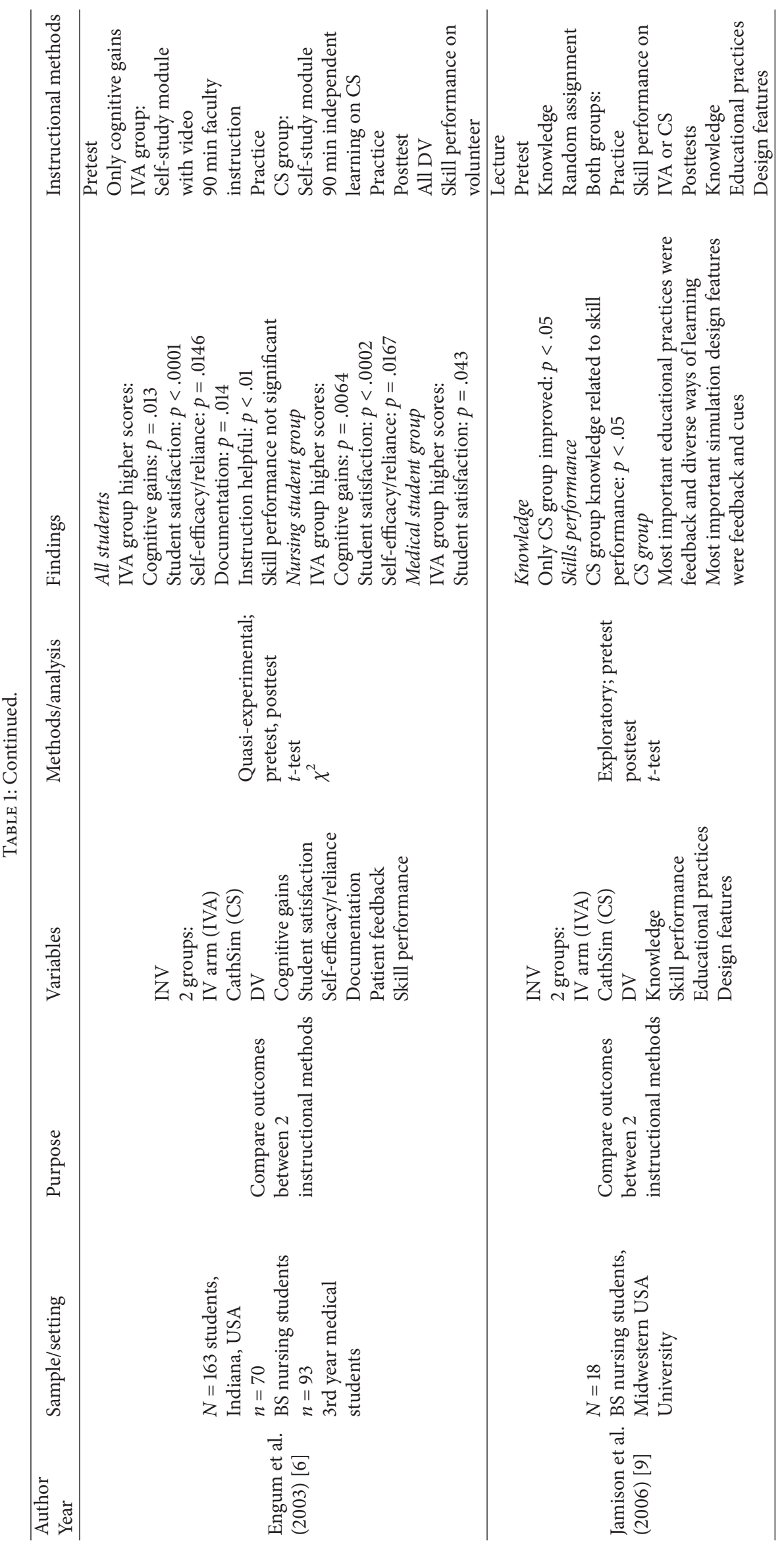




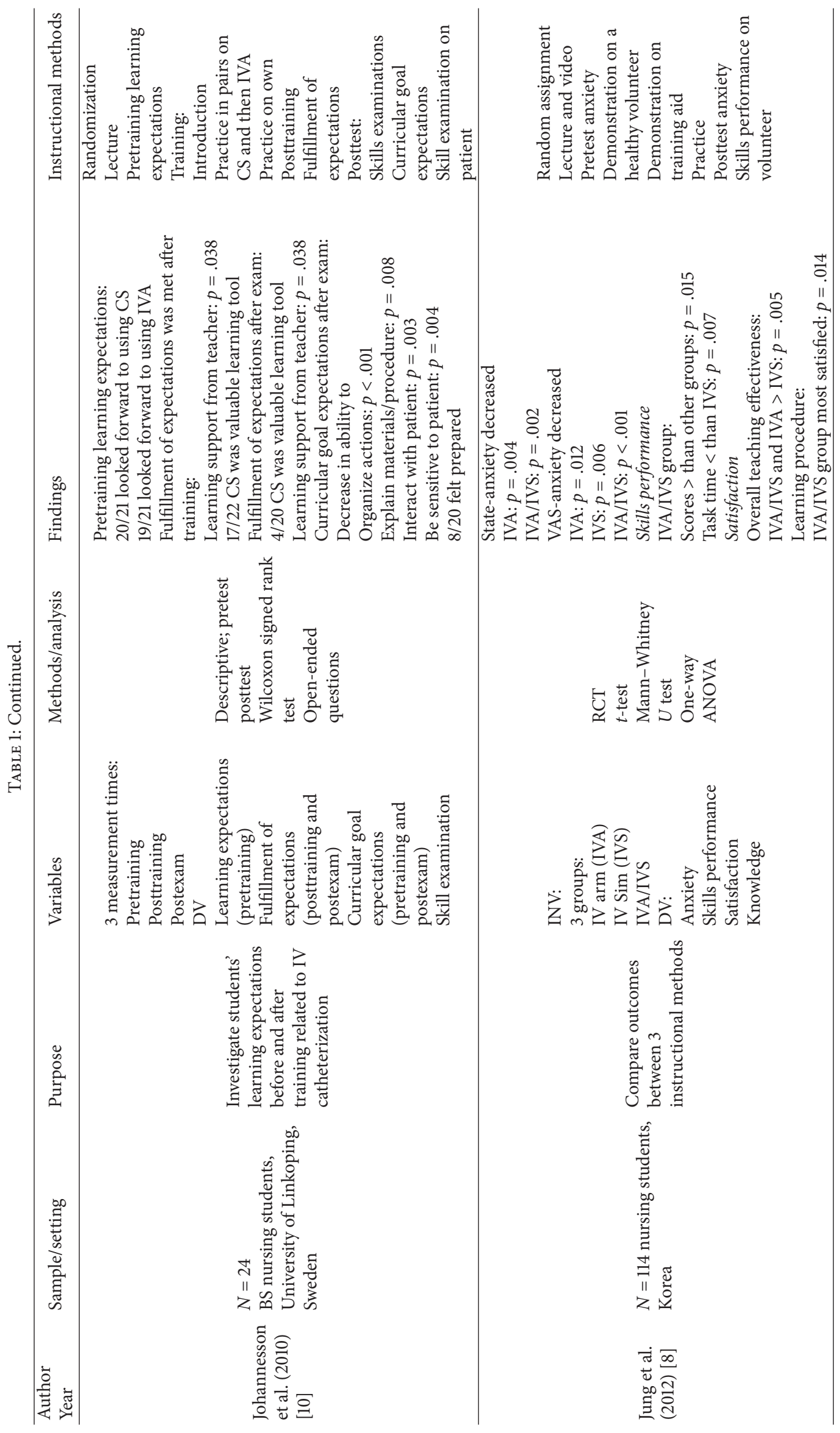




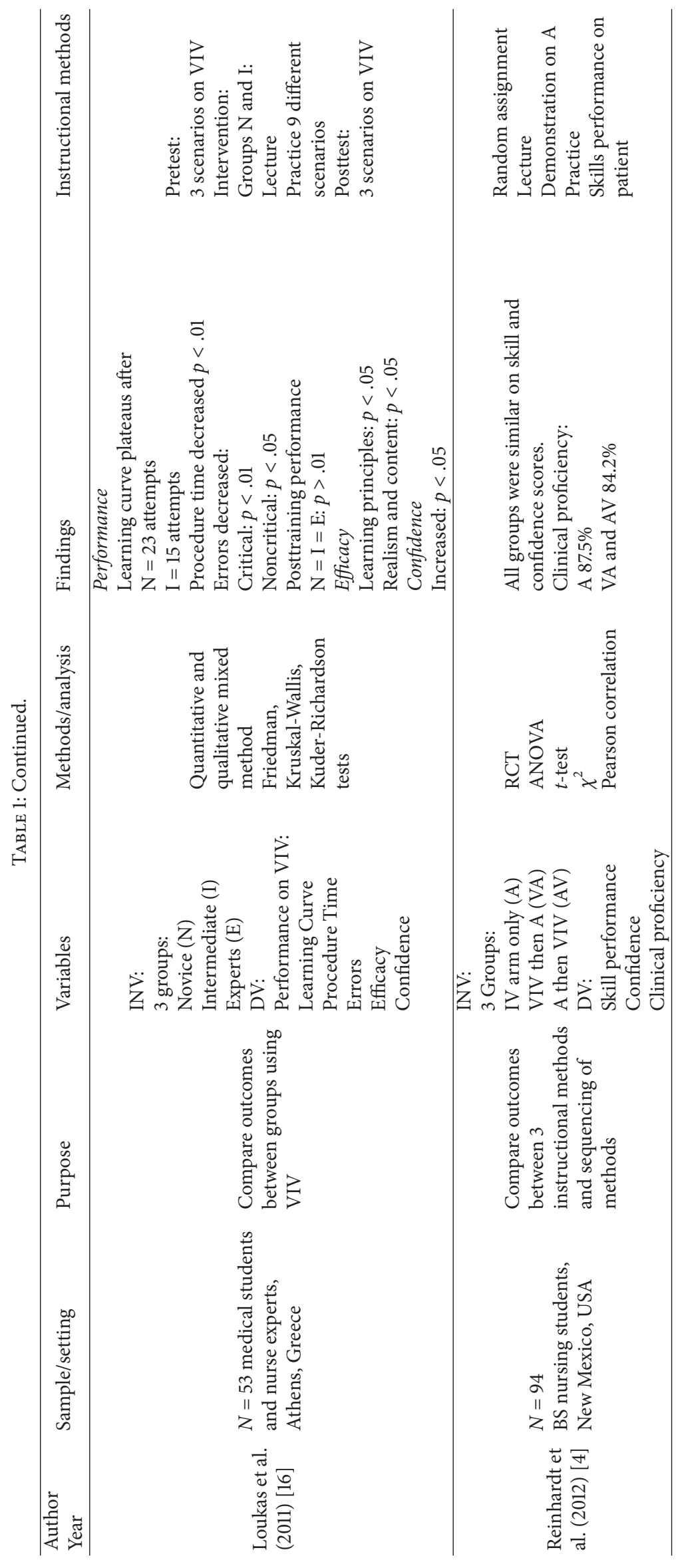




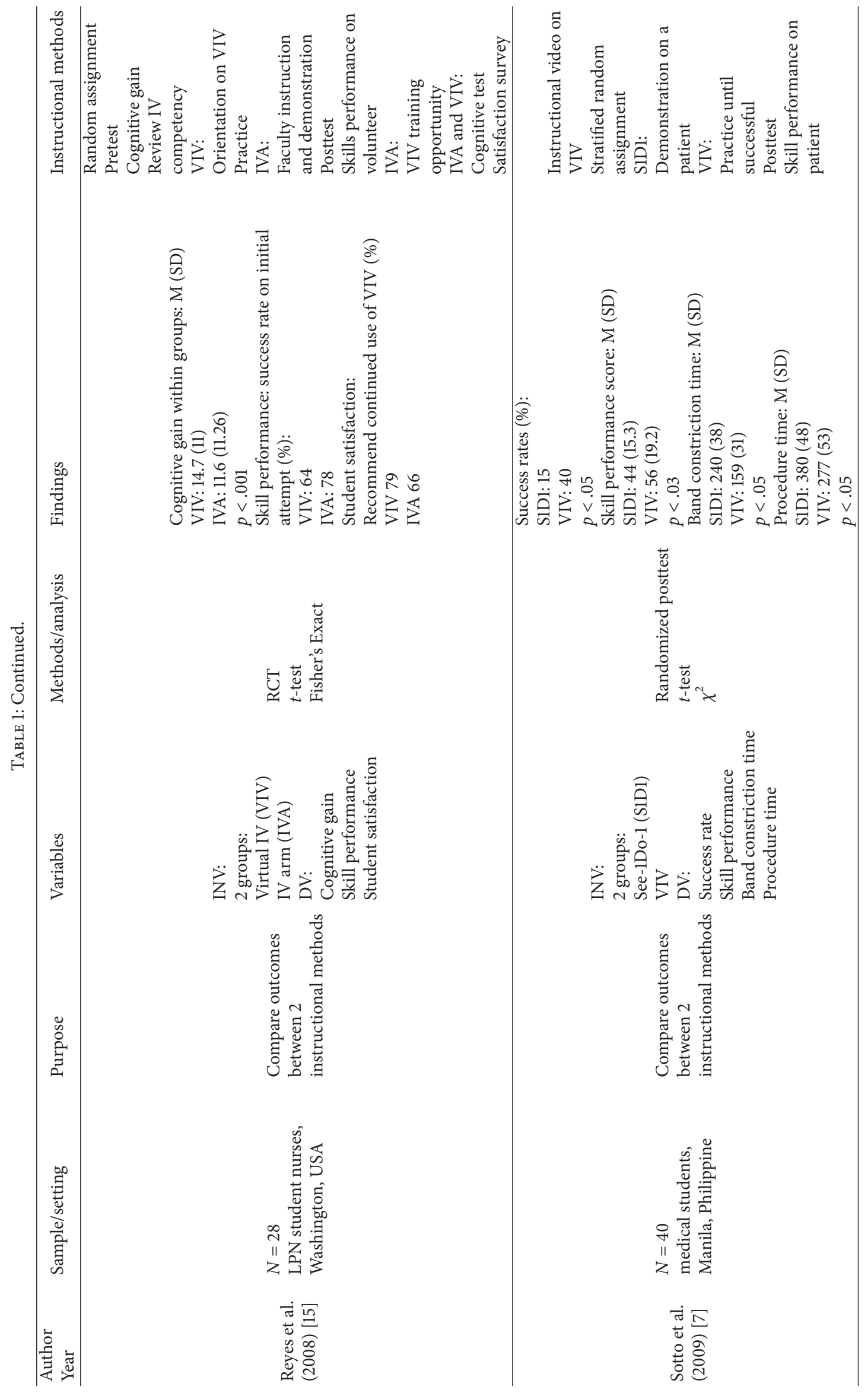




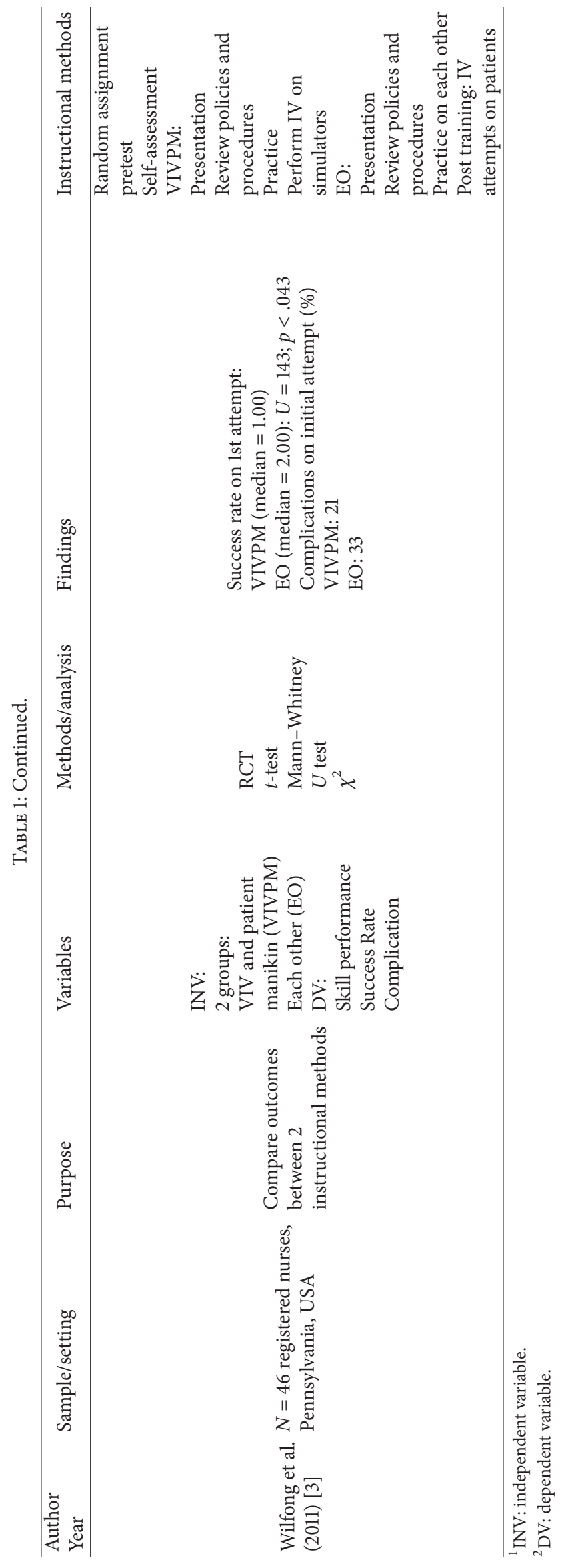


insertion. Wilfong et al. [3] noted that the VIV simulator group required fewer attempts in order to be successful at inserting an IV on a patient compared to the group who practiced on each other. Jung et al. [8] noted that students' procedure scores were higher if they trained on both the IV arm and haptic IV simulator and task time was shorter than those students using only the haptic IV simulator. Loukas and colleagues [16] compared outcomes between groups using the VIV simulator. The groups consisted of novice students (no IV experience) or intermediate graduates (less than ten IV insertions) and the outcomes measured included learning curve, errors, and task time on the VIV simulator. After training on the VIV simulator, both the novice and intermediate groups' scores for the outcomes measured were similar to those of a group of experts who were proficient in IV insertion $(p>.1)$.

4.1.4. Knowledge, Satisfaction, and Students' Expectations. Engum et al. [6] study results indicated that students' posttest scores and satisfaction scores were higher for the traditional methods group. In addition, both nursing and medical students preferred the traditional method of one-to-one facultystudent instruction over the CS system. Feedback from the traditional group indicated that they enjoyed working with faculty and touching the equipment but wanted more practice time in smaller groups with more instructors per group. Feedback from the CS group indicated that while the haptic IV simulator was not "real world," they enjoyed the simulator's variety of case scenarios, the instant feedback feature, and the ability to self-pace their own learning without harm to a patient. Overall, medical students were more accurate with IV placement but were more businesslike and task driven while the nursing students were more emotionally involved and concerned for their patients.

Two studies showed that the haptic groups' posttest knowledge scores improved [9] and assessment tool scores were greater [7] compared to the traditional groups. Reyes et al. [15] indicated that both groups (traditional and VIV) made cognitive gains. After posttesting [15], the traditional group was given the opportunity to train on the VIV simulator. Student satisfaction with the VIV experience showed that the group who initially trained on the VIV felt that the haptic IV simulator helped with clinical training (64\% versus $42 \%$ ), was time well spent ( $57 \%$ versus 50\%), and helped develop clinical skills (35\% versus 32\%) compared to the group who received training on the VIV after their traditional method training. The traditional method group felt that their VIV experience helped test decision making (57\% versus 50\%) and challenged critical thinking ( $41 \%$ versus $21 \%$ ) compared to the original VIV simulation group. Both groups recommended that VIV simulation be continued (VIV group 79\%; traditional group $66 \%)$.

Reyes et al. [15] concluded that IV performance was reinforced by practicing using the VIV simulator. Jung et al. [8] noted that repeated practice reduced students' anxiety while Chang et al. [13] found no differences in state anxiety levels between groups. Jung et al. [8] indicated that students who used both the IV arm and the haptic IV simulator were more satisfied with learning the procedure and that by combining both methods students were able to learn the skill in a timely manner using fewer consumables.

In the Johannesson et al. [10] study, students using a haptic simulator were asked an open-ended question regarding their learning expectations before training, after training, and after skill examination. Pretraining expectations included learning the practical technique, gaining confidence and insight, meeting the patient, and managing the situation. Posttraining findings noted that the simulator was helpful in building confidence and was a valuable learning tool. However, postskill examination results found the simulator was less valued as a learning tool. Overall, students' learning expectations were not met. Students felt that the haptic IV simulator did not equate with reality, that it limited their experience from a holistic perspective, and that the experience did not provide opportunity to practice communication skills. However, they expressed appreciation for the simulators' realism, variations in case scenarios, value in giving feedback, and opportunity for repeated practice. Students indicated that their awareness of patients' conditions and their effect on the patient's veins increased and they become more confident in their skills. The authors concluded that the haptic IV simulator was useful in the learning process when combined with the IV arm and that repeated practice built confidence in a safe environment while using active and independent learning. Loukas et al. [16] also noted that the haptic IV simulator was useful for learning the principles of IV cannulation and both Loukas et al. [16] and Wilfong et al. [3] noted that the haptic IV simulator increased selfconfidence.

4.2. Cost. Five articles in this review expressed concern regarding the cost of either the haptic IV simulator technology or the traditional approach (faculty/lab time intensive plus supplies) when teaching IV insertion. As of July 2015, the approximate cost of one haptic IV simulator ranges between US\$20,000-US\$25,000. Jung et al. [8] note that more economical training methods are needed in order to prepare practitioners who are skilled using learning methods that are effective.

Wilfong et al. [3] identified the cost of the haptic IV simulator as being an issue in developing countries but also mentioned that the traditional method of teaching IV insertion requires a high faculty-to-student ratio which is also costly. Bowyer et al. [5] noted that haptic IV simulators are as effective in teaching IV insertion as the traditional method, which consists of didactic instruction followed by practice on a simulated arm or practicing the procedure on another student or patient. However, the traditional method is costlier in terms of supplies, equipment, and faculty time [5]. Reinhardt et al. [4] addressed the cost of the haptic IV simulator in comparison to the IV training arm while Engum et al. [6] noted the importance of keeping cost down in order to gain academic support. Jung et al. [8] stated that haptic IV simulators are cost effective as students do not need to use consumables during the learning process and they provide repeated educational opportunities for student practice. Jung et al. [8] recommended combining the haptic IV simulator with the IV arm to assist students with learning skills in a timely manner. 


\section{Discussion}

Current use of haptic IV simulators and traditional training methods continue to have different outcomes. For this review, some of the studies indicated a decrease in student anxiety levels and an increase in cognitive gains with practice but these results were not related to the method of IV instruction. Other studies indicated performance improvement by a decrease in insertion time and band constriction time with the use of the haptic IV simulator.

Students' learning expectations related to the haptic IV simulator were high. They presumed that the technology was going to teach all aspects of IV insertion, including successful cannulation, when in reality the IV simulator teaches the process. Students continue to need faculty support and feedback during practice on the IV arm but during the learning process other options may be more feasible and cost effective. It is interesting to note that, even with the availability of IV plastic arms and haptic simulators, some educational programs still have students practicing on each other as well as on patients.

Intravenous catheter insertion is one of the most challenging skills taught in nursing school. A nurse's ability to insert an IV successfully depends on experience, number of insertions performed, and patient factors such as veins that roll or are resistant to venipuncture and color or turgor of the skin [17]. More importantly, the patient's perceptions of how caring the nurse is can be linked to his/hers beliefs about the nurse's skill in performing the procedure [17].

Simulation is an educational strategy that provides opportunities for students to practice skills in a risk-free environment without fear of harming patients [18]. Haptic IV simulators are useful in learning the process and skills training for IV insertion and cannulation $[3,5,7,9,10,15,16]$. Haptic IV simulators allow students to practice IV procedures repeatedly on complex patient scenarios [18] while developing proficiency and critical learning skills without using costly consumables and faculty time. While there is little information on the cost of the haptic IV simulators and virtually no information regarding the cost of consumables or faculty time needed to teach this skill, a cost comparison between these instructional methods would be beneficial.

Alexandrou et al. [19] concluded in their review of the literature on the training of vascular access for undergraduate clinicians that no method of training was found to be superior to another. However, the results of the current review lean towards more positive outcomes. The use of haptic IV simulators to teach the process of inserting an IV decreased the number of attempts needed to be successful when inserting an IV on patients [3] and reduced the total IV insertion procedure time and band constriction time $[7,16]$.

\section{Conclusion}

Based on this review and noted by Johannesson et al. [10] and Jung et al. [8] the best IV instructional method would combine the haptic IV simulator followed by practice time on the IV arm. During the learning process, group work while using the haptic IV simulator may be one alternative to decrease cost while providing support to group members. Only one of the studies in this review [10] trained 2 students together for one hour while using the CS followed by practice on an IV arm. Further research using cooperative learning or other active learning strategies while using the haptic IV simulator may be beneficial and could potentially reduce the overall cost of learning IV insertion.

\section{Competing Interests}

The authors declare that they have no competing interests.

\section{References}

[1] R. S. Jones, A. Simmons, G. L. Boykin, D. Stamper, and J. C. Thompson, "Measuring intravenous cannulation skills of practical nursing students using rubber mannequin intravenous training arms," Military Medicine, vol. 179, no. 11, pp. 1361-1367, 2014.

[2] G. A. Da Silva, S. Priebe, and F. N. Dias, "Benefits of establishing an intravenous team and the standardization of peripheral intravenous catheters," Journal of Infusion Nursing, vol. 33, no. 3, pp. 156-160, 2010.

[3] D. N. Wilfong, D. J. Falsetti, J. L. McKinnon, L. H. Daniel, and Q. Wan, "The effects of virtual intravenous and patient simulator training compared to the traditional approach of teaching nurses," Journal of Infusion Nursing, vol. 34, no. 1, pp. 55-62, 2011.

[4] A. C. Reinhardt, I. L. Mullins, C. De Blieck, and P. Schultz, "IV insertion simulation: confidence, skill, and performance," Clinical Simulation in Nursing, vol. 8, no. 5, pp. e157-e167, 2012.

[5] M. Bowyer, E. Pimentel, J. Fellows et al., “Teaching intravenous cannulation to medical students: comparative analysis of two simulators and two traditional educational approaches," in Ebook: Medicine Meets Virtual Reality 13, vol. 111 of Studies in Health Technology \& Informatics, pp. 57-63, 2005, http://ebooks .iospress.nl/volumearticle/10037.

[6] S. A. Engum, P. Jeffries, and L. Fisher, "Intravenous catheter training system: computer-based education versus traditional learning methods," The American Journal of Surgery, vol. 186, no. 1, pp. 67-74, 2003.

[7] J. Sotto, E. Ayuste, M. Bowyer et al., "Exporting simulation technology to the Philippines: a comparative study of traditional versus simulated methods for teaching intravenous cannulation," Studies in Health Technology \& Informatics, vol. 17, pp. 346-351, 2009.

[8] E.-Y. Jung, D. K. Park, Y. H. Lee, H. S. Jo, Y. S. Lim, and R. W. Park, "Evaluation of practical exercises using an intravenous simulator incorporating virtual reality and haptics device technologies," Nurse Education Today, vol. 32, no. 4, pp. 458-463, 2012.

[9] R. J. Jamison, M. T. Hovancsek, and J. M. Clochesy, "A pilot study assessing simulation using two simulation methods for teaching intravenous cannulation," Clinical Simulation in Nursing, vol. 2, no. 1, pp. e9-e12, 2006.

[10] E. Johannesson, M. Olsson, G. Petersson, and C. Silén, "Learning features in computer simulation skills training," Nurse Education in Practice, vol. 10, no. 5, pp. 268-273, 2010.

[11] T. Rutherford-Hemming, "Simulation methodology in nursing education and adult learning theory," Adult Learning, vol. 23, no. 3, pp. 129-137, 2012. 
[12] S. Sportsman, "Competency education and validation in the United States: what should nurses know?" Nursing forum, vol. 45, no. 3, pp. 140-149, 2010.

[13] K. K.-P. Chang, J. W.-Y. Chung, and T. K.-S. Wong, "Learning intravenous cannulation: a comparison of the conventional method and the CathSim Intravenous Training System," The Journal of Clinical Nursing, vol. 11, no. 1, pp. 73-78, 2002.

[14] R. Whittemore and K. Knafl, "The integrative review: updated methodology," Journal of Advanced Nursing, vol. 52, no. 5, pp. 546-553, 2005.

[15] S. D. Reyes, K. Stillsmoking, and D. Chadwick-Hopkins, "Implementation and evaluation of a virtual simulator system: teaching intravenous skills," Clinical Simulation in Nursing, vol. 4, no. 1, pp. e43-e49, 2008.

[16] C. Loukas, N. Nikiteas, M. Kanakis, and E. Georgiou, "Evaluating the effectiveness of virtual reality simulation training in intravenous cannulation," Simulation in Healthcare, vol. 6, no. 4, pp. 213-217, 2011.

[17] A. F. Jacobson and E. H. Winslow, "Variables influencing intravenous catheter insertion difficulty and failure: an analysis of 339 intravenous catheter insertions," Heart and Lung: Journal of Acute and Critical Care, vol. 34, no. 5, pp. 345-359, 2005.

[18] S. Decker, S. Sportsman, L. Puetz, and L. Billings, “The evolution of simulation and its contribution to competency," The Journal of Continuing Education in Nursing, vol. 39, no. 2, pp. 74-80, 2008.

[19] E. Alexandrou, L. Ramjan, J. Murphy, L. Hunt, V. Betihavas, and S. A. Frost, "Training of undergraduate clinicians in vascular access: an integrative review," JAVA - Journal of the Association for Vascular Access, vol. 17, no. 3, pp. 146-158, 2012. 


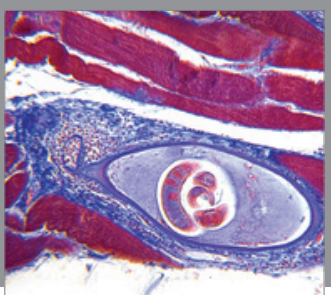

Gastroenterology

Research and Practice
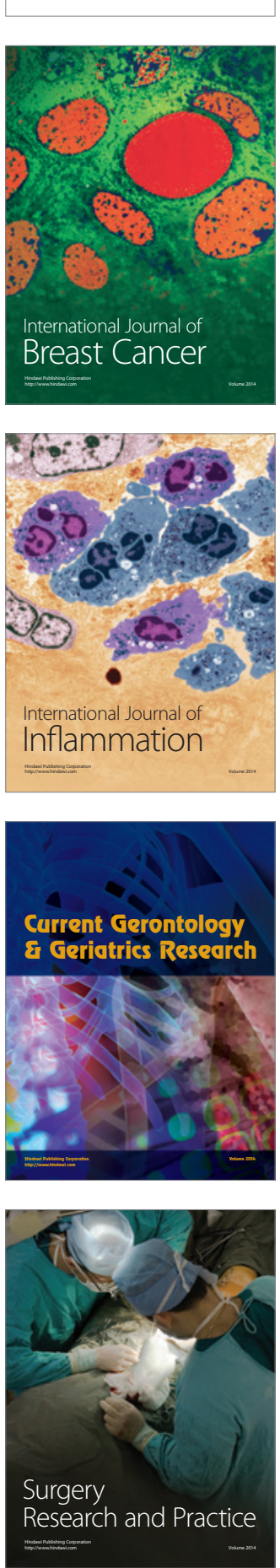

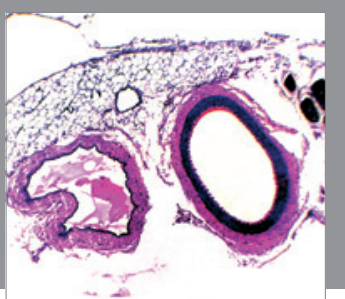

International Journal of Hypertension
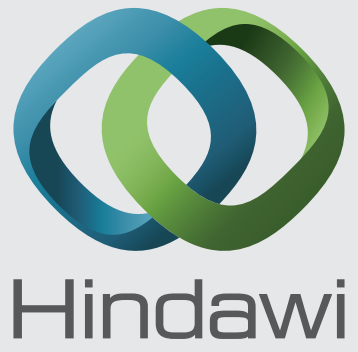

Submit your manuscripts at

https://www.hindawi.com
The Scientific Nursing

World Journal Research and Practice

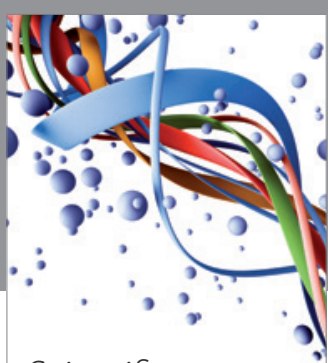

Scientifica

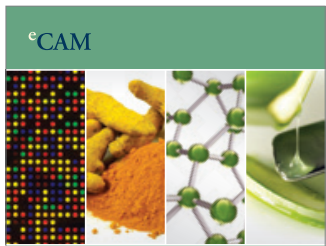

Evidence-Based

Complementary and

Alternative Medicine
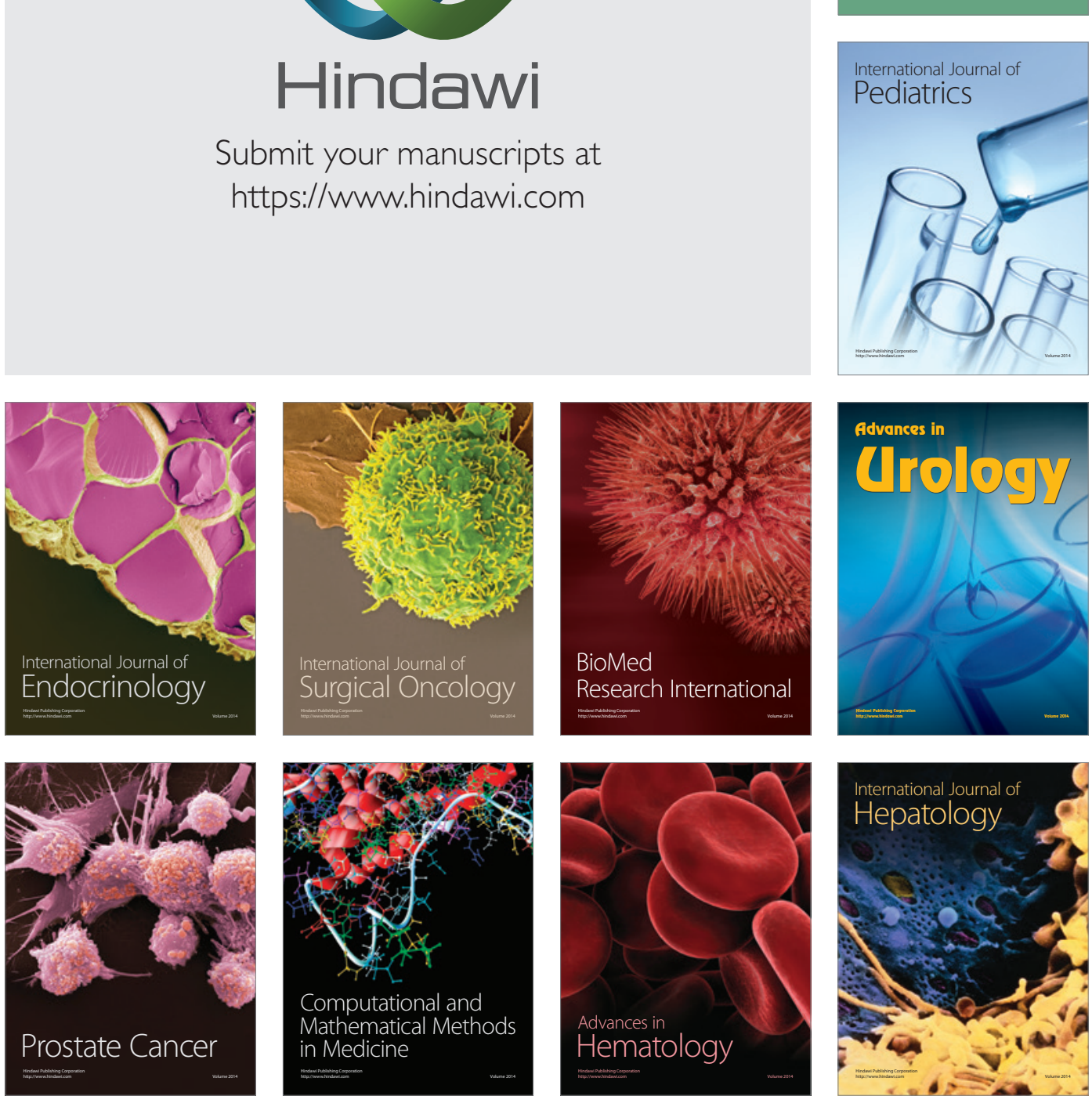